\title{
OP31
}

\section{APPROACH TO ANALYSE SEASONAL AND GEOGRAPHICAL VARIATIONS IN DAYLIGHT ILLUMINANTS}

Martine Knoop et al.

DOI 10.25039/x46.2019.OP31

from

CIE x046:2019

Proceedings

of the

29th CIE SESSION

Washington D.C., USA, June 14 - 22, 2019

(DOI 10.25039/x46.2019)

The paper has been presented at the 29th CIE Session, Washington D.C., USA, June 14-22, 2019. It has not been peer-reviewed by CIE.

(C) CIE 2019

All rights reserved. Unless otherwise specified, no part of this publication may be reproduced or utilized in any form or by any means, electronic or mechanical, including photocopying and microfilm, without permission in writing from CIE Central Bureau at the address below. Any mention of organizations or products does not imply endorsement by the CIE.

This paper is made available open access for individual use. However, in all other cases all rights are reserved unless explicit permission is sought from and given by the CIE.

CIE Central Bureau

Babenbergerstrasse 9

A-1010 Vienna

Austria

Tel.: +43 17143187

e-mail: ciecb@cie.co.at

www.cie.co.at 


\title{
APPROACH TO ANALYSE SEASONAL AND GEOGRAPHICAL VARIATIONS IN DAYLIGHT ILLUMINANTS
}

\author{
Knoop, M. ${ }^{1}$, Weber, N. ${ }^{1}$, Diakite, A.K. ${ }^{1}$ \\ 1 Technische Universität Berlin, Chair of Lighting Technology, Berlin, GERMANY
}

martine.knoop@tu-berlin.de

DOI 10.25039/x46.2019.OP31

\begin{abstract}
Based on 622 spectral measurements, a reconstruction approach for spectral power distributions of daylight was proposed in 1964. This procedure allows to derive the spectral power distribution of daylight illuminants from their chromaticity coordinates or correlated colour temperature. It suggests that inexpensive sensors can be used to measure daylight and a representation of colour characteristics of daylight can be done with just one single value, without large errors. The reconstruction approach was adopted by the CIE, nonetheless, emphasising that geographical and seasonal variations might exist. Up until today, these variations are investigated in single studies. This paper includes a review of relevant parameters that affect the reconstruction procedure and proposes a template for spectral measurements, to be used in a large worldwide measurement campaign, to modify or complement the existing CIE approach for reconstitution of daylight's spectral power distribution.
\end{abstract}

Keywords: daylight locus, SPD reconstruction, spectral measurements, template

\section{Introduction}

Spectral power distributions of daylight have a characteristic profile, and even though daylight might vary amongst different geographical locations, similarities can be found (Judd et al. 1964, Hernández-Andrés et al. 1998). Chromaticities of daylight lay on a curve more or less parallel to the Planckian curve in the CIE x,y chromaticity diagram. Judd et al. proposed a method for reconstruction of daylight spectral power distributions between $300 \mathrm{~nm}-830 \mathrm{~nm}$, using characteristic vectors derived from 622 spectral sky measurements of skylight with and without sunlight conducted in Rochester (US), Enfield (UK) and Ottawa (CA). This reconstruction method was adopted by the CIE to represent the spectral characteristics of outdoor daylighting conditions (Figure 1) (CIE 1967, CIE 2018), for $x_{D}$ being within the range of 0,250 to 0,380 and correlated colour temperatures between $4000 \mathrm{~K}$ and $25000 \mathrm{~K}$. Each colour point on the daylight locus is assigned a unique correlated colour temperature (CCT) and a specific spectral power distribution (SPD).

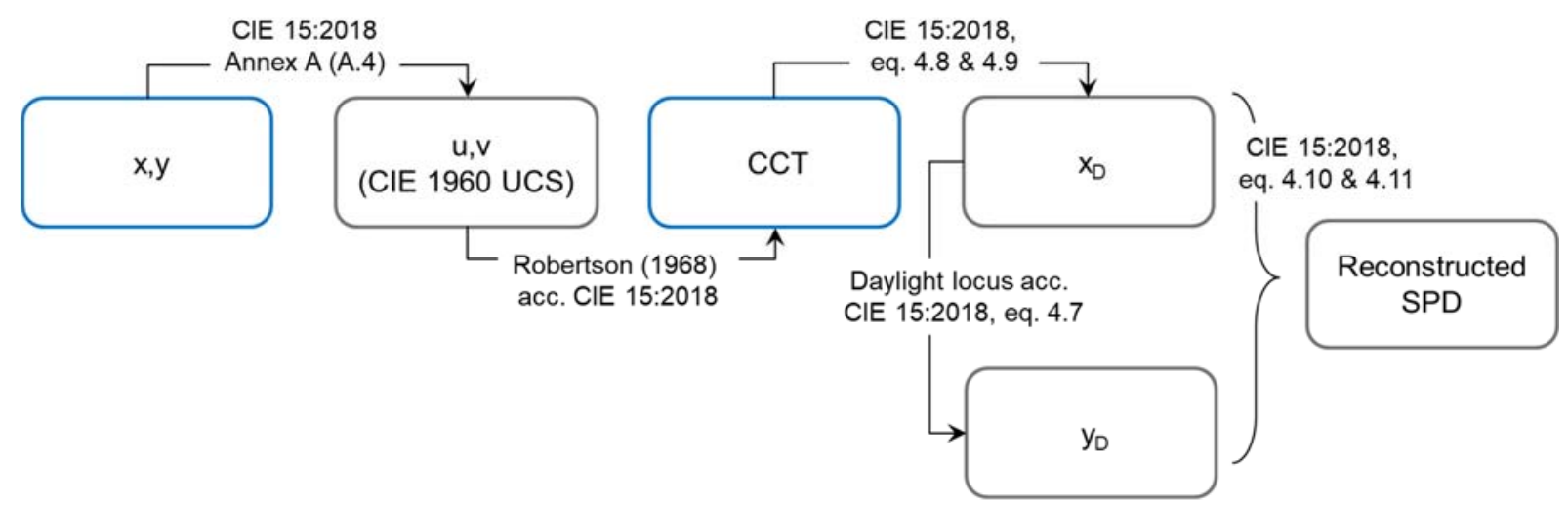

Figure 1 - Approach to reconstruct spectral power distributions (SPD) from chromaticity coordinates $(x, y)$ or correlated colour temperature (CCT) 
Reconstitution of an SPD from a CCT or colour point allows, for example, the use of inexpensive colour sensors to obtain an approximate SPD without having to resort to spectroradiometers. The then acquired spectrally resolved daylight data can be weighted with any weighting function. This provides, for instance, opportunities for light dose measurements in daylight studies in the determination of non-visual, ipRGC-influenced light (IIL) responses to daylight, but also for lighting control systems that support these effects. It also offers possibilities on the representation side. The daylight's SPD can be reflected in only one value, its CCT. This is useful in the presentation of daylight conditions, as for example used in spectral sky models. Again, spectrally resolved daylight data can be derived from this information and be evaluated depending on the need or application.

However, it is known that the reconstituted SPDs for daylight illuminants are not just average SPDs, but they are also subject to seasonal and geographical variations (CIE 015:2018). A number of researchers confirmed with various daylight measurements, that local daylight loci might deviate from the CIE daylight locus (e.g. Winch et al. 1966, Dixon 1978, Sekine 1991, Kobayashi et al. 1996, Hernández-Andrés et al. 2001-1, Hernández-Andrés et al. 2001-2, Rusnák 2014, Diakite et. al. 2018), of which a few are included in Figure 2. A deviation of the daylight locus represents a shift in chromaticity, which is a result of the SPD, and thus affects the reconstruction procedure. Some researchers evaluated the CIE reconstruction approach and found local inaccuracies for both ends of the visual spectrum (Hernández-Andrés et al. 1998, Chain 2004).
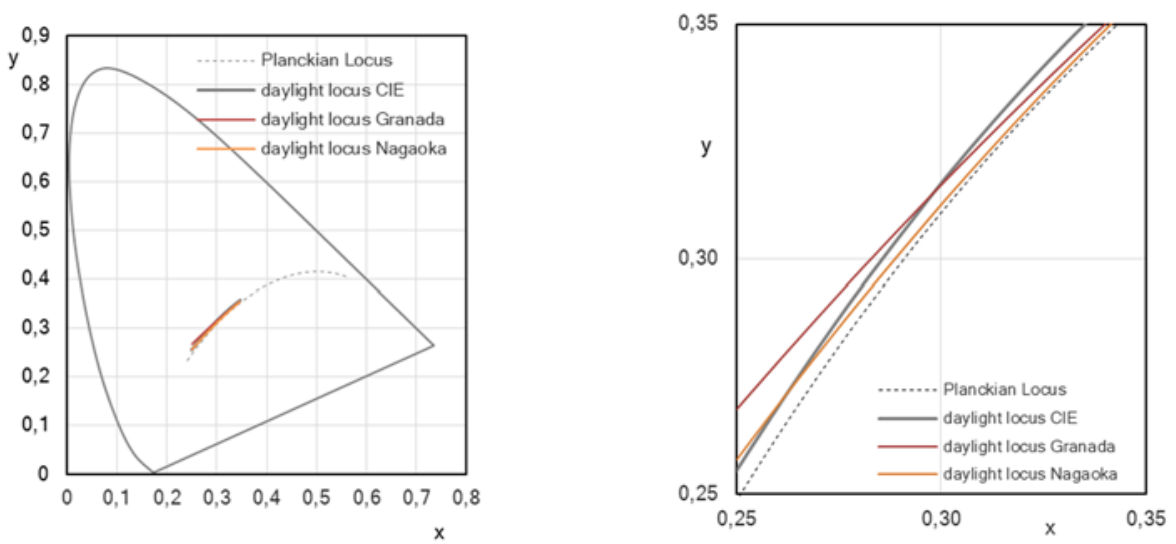

Figure 2 - Daylight loci according to CIE 015:2018 and measurements in Granada, Spain (Hernández-Andrés et al. 2001-1) and Nagaoka, Japan (Sekine 1991)

As the short wavelength contribution is of specific interest for the IIL responses, the reconstitution of SPDs as adopted by the CIE needs to be verified and extended. HernándezAndrés et al. (1998) compared reconstruction proposals for SPDs by the CIE (based on 622 measurements collected by Judd et. al 1964), Sastri and Das (187 measurements in India, published in 1968) and Dixon (290 + 240 measurements in Australia, published in 1978) using 252 daylight measurements conducted in Granada (Spain). The quality of reconstruction was represented with the Goodness-of-Fit Coefficient (GFC). The evaluation showed that the CIE reconstruction is better than those proposed by others, but still did not achieve optimal GFCs.

An evaluation of the CIE reconstruction approach was repeated with daylight measurements of the Technische Universität Berlin. These measurements were also used to define a local daylight locus as well as eigenvectors for a local reconstruction procedure.

The measurements were conducted at the daylight measuring site of the Technische Universität Berlin ( $52^{\circ} 31^{\prime} \mathrm{N}, 13^{\circ} 20^{\prime} \mathrm{E}$, altitude $50 \mathrm{~m}$ ), in an urban setting with medium height buildings and a mixture of low luminous turbidity and polluted atmosphere (Aydinli et al. 2018, confirmed by the occurrence of CIE General Sky Type 12 and Sky Type 13 under clear sky conditions, reported in Diakite and Knoop 2019). 

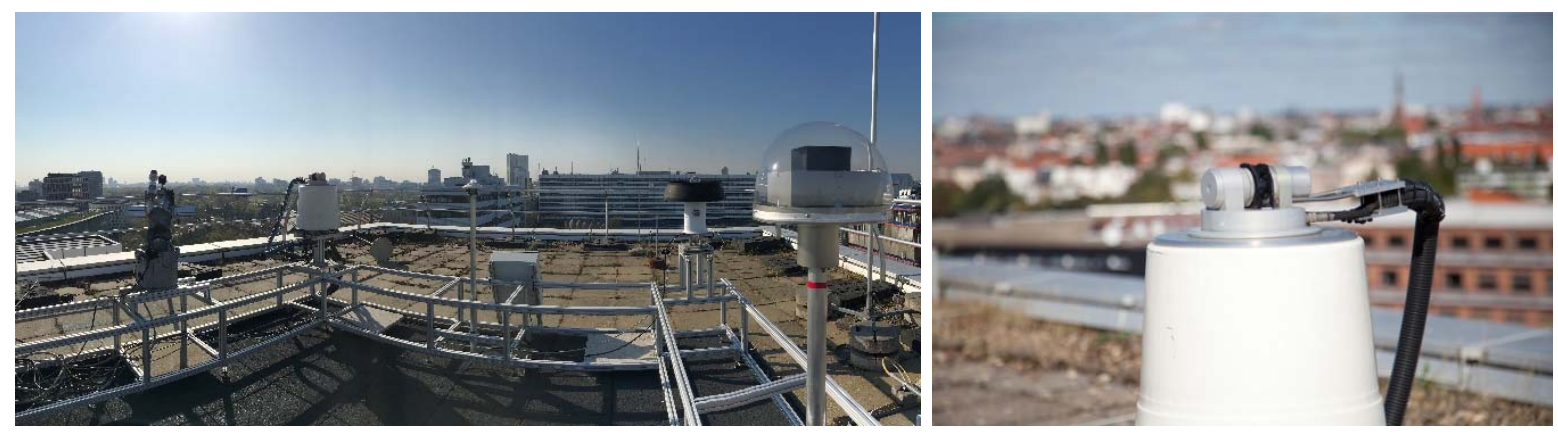

Figure 3 - Daylight measuring site (left) and spectral sky scanner (right) of the Technische Universität Berlin

Spectral radiance measurements of skylight without direct sunlight were performed by a custom-made spectral sky scanner with an array spectroradiometer (Zeiss Multi-ChannelSpectrometer MCS CCD with a Hamamatsu back-thinned CCD) using a step size of approximately $0,8 \mathrm{~nm}$ between $280 \mathrm{~nm}$ and $980 \mathrm{~nm}$. With this device a complete scan of 145 sky patches according to Tregenza (1987) and CIE (1994) is scanned within one minute, scans are carried out every two minutes from sunrise to sunset. The input optic has an aperture angle of $10^{\circ}$. The measuring equipment was characterised (relative and absolute) in the laboratory of the Technische Universität Berlin, using a FEL lamp for the spectral, relative characterisation, and a large uniform LED light source, with a prominent short-wavelength component in combination with a calibrated luminance meter for the absolute characterisation (Knoop et al. 2017).

The spectral sky scanner measurements are performed since 2014 and are still ongoing. For this paper, measurement data of 2015 and 2016 for a bandwidth of $380 \mathrm{~nm}-780 \mathrm{~nm}$ were analysed. This period of time included all seasons and weather conditions; clear, intermediate and overcast skies (Diakite and Knoop 2019).

A selection of measurements from this period of time was made:

- The daylight measuring site's horizon has very little obstruction, nonetheless the lowest almucantar is not included in the evaluation to reduce influences due to haziness and obstruction.

- To consider areas of the sky that are not exposed to direct sunlight throughout the year regardless of the sun's position, a selection of patches with north orientation was made (patches $70,73,76,93,96,99,118,132,142$ according to Tregenza 2004, Figure 2a, p. 274, blue patches in figure to the right).

- Of the measurements from sunrise to sunset

- only measurements starting on the hour were included in the analysis, and

- measurements at times with a solar altitude angle $\gamma_{s}<5^{\circ}$ were left out, to exclude measurement inaccuracies due to low signal level during sunrise and sunset (Chain 2004).

This resulted in 2559 scans with 22419 SPDs for 2015 and 2565 scans with 23085 SPDs for 2016 (Diakite et al. 2018).

A preliminary daylight locus for Berlin (Figure 5) and corresponding eigenvectors were determined from the measurements in 2016 and validated with measurements from 2015. The quality of reconstruction was evaluated by means of the GFC (equation 1), comparing measurement data taken in Berlin in 2015 to reconstructed SPDs using the CIE015:2018 daylight locus and eigenvectors (based on Judd et al. 1964), as well as the preliminary Berlin daylight locus and eigenvectors. Examples are shown in Figure 4. A significantly higher mean GFC was achieved by the optimised reconstruction method (Diakite et al. 2018). The daylight locus for Berlin mainly deviates from the CIE daylight locus at high correlated colour temperatures. This confirms findings of other daylight measuring sites, even though not all in the same direction, as can be seen from Figure 2 and Figure 5. 

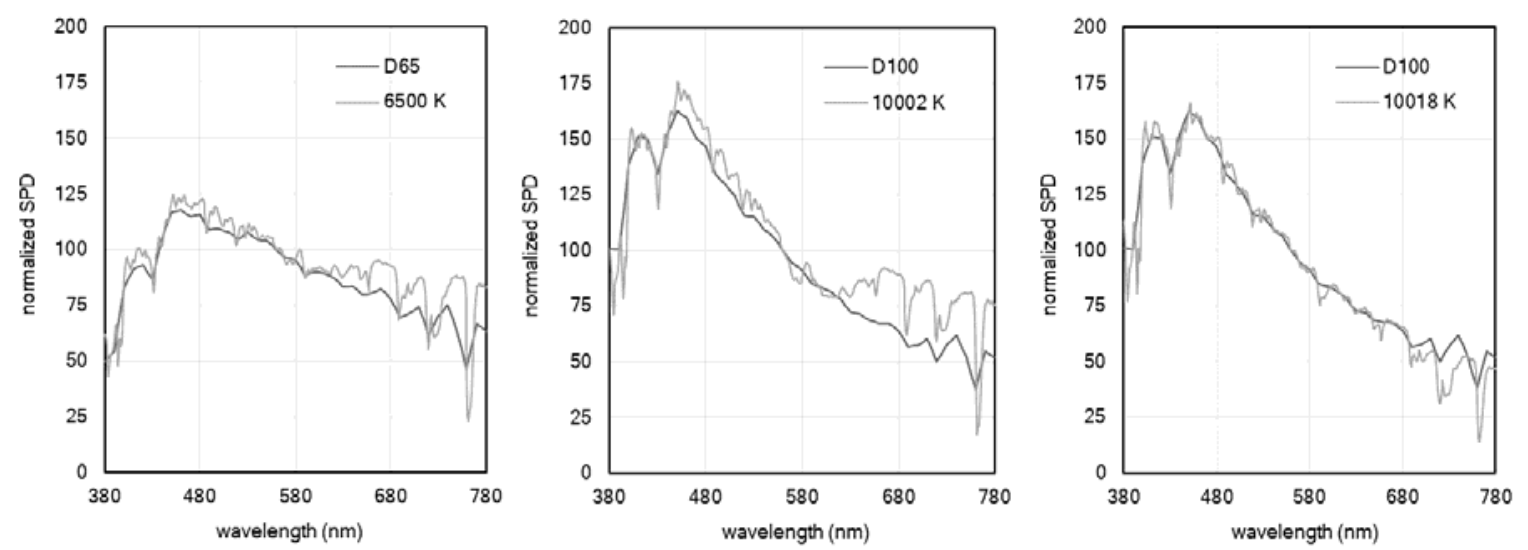

Figure 4 - Examples for measured SPDs and the reconstructed SPDs using the CIE approach

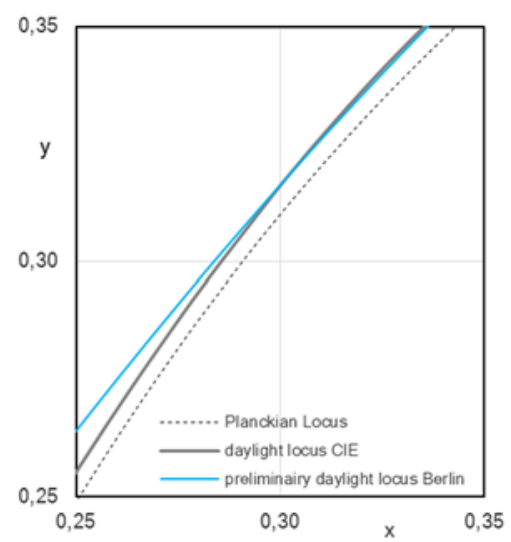

Figure 5 - Preliminary daylight locus for Berlin, in comparison to the CIE daylight locus

Practically this means, for example, that it is not clear if an appropriate assessment of IIL effects can be derived from measurements with colour sensors or CCT values from spectral sky models, using the current CIE approach to reconstitute SPDs.

\section{Development of a measurement template}

To investigate both geographical and seasonal variations, a large worldwide measurement campaign is planned. According to Henderson (1977) daylight loci should be based on a homogeneous data basis. To collect measurement data from different project partners, it is important to document relevant parameters and define the measurement procedure. For this, a documentation and measurement template is drawn up. The relevant parameters to document are partly obtained from a literature review, partly based on an analysis of spectral daylight measurements.

\subsection{Summary of the literature review}

From a literature review, looking into papers on spectral daylight measurements which were conducted in the past 60 years (paper available on request), following possible relevant parameters to document were deduced:

Type of measurement: Hernández-Andrés et al. (2001-1, 2001-2) proposed different daylight loci depending on the type of measurement or assessment. One local daylight locus for global, hemispheric, spectral irradiance, including both skylight and combinations of skylight and sunlight, another local daylight locus for spectral radiance, derived from $3^{\circ}$ narrow field-of-view, patch, measurements. Dubnicka et al. (2017) propose two distinct daylight loci as well, based on patch measurements, but reflecting an assumed difference between spectral irradiance and spectral radiance (Figure 7). 
Detector orientation: A number of researchers, who conducted patch or integral spectral measurements towards one or more orientations, most of them with an orientation turned away from the sun, inclined by $45^{\circ}$, report local bandwidths for CCTs varying in a range from approximately $4000 \mathrm{~K}$ to $100000 \mathrm{~K}$ (e.g. Nayatani and Wyszecki 1963, Collins 1965, Winch et al. 1966, Sastri and Das 1968, Hernández-Andrés et al. 2001-1). Horizontally positioned integral measurements cover a much smaller CCT bandwidth (e.g. Henderson and Hodgkiss 1964, Collins 1965). The impact of orientation on SPDs was not analysed.

Atmosphere: According to Hisdal (1987) and Peyvandi et al. (2016), ozone absorption, optical thickness and cloud cover has an impact on the SPD of daylight. Especially the UV part of the SPD is significantly affected by the length of the path through the atmosphere, and variations related to season and geographic location can be found (e.g. Kok et al. 1978, Dixon 1978).

Spectral range and spectral resolution were evaluated by Hernández-Andrés et al. (1998), who concluded that the spectral range has an impact on the GFC of the spectral reconstruction, and the spectral resolution should be minimum $5 \mathrm{~nm}$, instead of the current $10 \mathrm{~nm}$. No seasonal variations in daylight chromaticities were found in one-year measurements (Hernández-Andrés et al. 2001-2). There is no confirmation that local terrain colour is of importance (HernándezAndrés et al. 2001-2), which is suggested by Sekine (1991).

\subsection{Outline of the measurement analysis}

To obtain a homogeneous data basis it is proposed to document measurement details, to be able to adopt (local) daylight loci or include modifications in the CIE daylight locus, for parameters relevant to the SPD of daylight. The literature review indicated that type of measurement and atmospheric characteristics could have an impact on the collected data. The measurement analysis therefore addressed the impact of the sensor's field-of-view and orientation and solar altitude. It also included weather condition, representative for cloud cover, to account for possible other atmospheric related aspects, even though no significant impact of weather condition on global spectral irradiance measurements was found in the literature reviewed. The analysis build upon further evaluation of the 2015 measurements, conducted as described in the introduction, considering these parameter (Table 1).

Table 1 - Measurement analysis overview

\begin{tabular}{|c|c|c|c|c|c|c|}
\hline $\begin{array}{l}\text { Type of } \\
\text { measurement }\end{array}$ & $\begin{array}{l}\text { Direction } \\
\text { (cf Figure 8) }\end{array}$ & $\begin{array}{l}\text { Solar } \\
\text { altitude }\end{array}$ & $\begin{array}{l}\text { CIE Sky } \\
\text { Type }\end{array}$ & $\begin{array}{l}\text { Period of } \\
\text { time }\end{array}$ & $\begin{array}{l}\text { Data } \\
\text { sets }\end{array}$ & $\begin{array}{l}\text { Exemplary } \\
\text { results in }\end{array}$ \\
\hline $\begin{array}{l}\text { Spectral radiance, } \\
\text { opening angle } 2^{\circ} \\
\text { (patch) } \\
\text { Global spectral } \\
\text { irradiance, } 180^{\circ}\end{array}$ & Zenith & $\gamma_{s}>15^{\circ}$ & Clear sky & $\begin{array}{l}\text { February \& } \\
\text { April } 2019\end{array}$ & $\begin{array}{l}1218 \\
(602+ \\
616)\end{array}$ & Figure 7 \\
\hline $\begin{array}{l}\text { Spectral radiance, } \\
\text { opening angle } 10^{\circ}\end{array}$ & $\begin{array}{l}145 \text { (zenith) } \\
116 \\
045\end{array}$ & $\gamma_{s}>15^{\circ}$ & $\begin{array}{l}\text { CIE Sky } 3 \\
\text { overcast sky } \\
\text { CIE Sky } 12 \\
\text { clear sky }\end{array}$ & 2015 & $\begin{array}{l}19398 \\
(6470+ \\
6458+ \\
6470)\end{array}$ & Figure 8 \\
\hline $\begin{array}{l}\text { Spectral radiance, } \\
\text { opening angle } 10^{\circ}\end{array}$ & $\begin{array}{l}145 \text { (zenith) } \\
118\end{array}$ & $\begin{array}{l}\gamma_{s}<15^{\circ} \\
\gamma_{s}>15^{\circ}\end{array}$ & $\begin{array}{l}\text { CIE Sky } 12 \\
\text { clear sky }\end{array}$ & 2015 & $\begin{array}{l}6016 \\
(3076+ \\
2940)\end{array}$ & $\begin{array}{l}\text { Figure } 10, \\
\text { Figure } 9\end{array}$ \\
\hline $\begin{array}{l}\text { Spectral radiance, } \\
\text { opening angle } 10^{\circ}\end{array}$ & 145 (zenith) & $\gamma_{s}>15^{\circ}$ & $\begin{array}{l}\text { CIE Sky } 3 \\
\text { overcast sky } \\
\text { CIE Sky } 12 \\
\text { clear sky }\end{array}$ & 2015 & $\begin{array}{l}7482 \\
(6012+ \\
1470)\end{array}$ & Figure 11 \\
\hline $\begin{array}{l}\text { Spectral radiance, } \\
\text { opening angle } 10^{\circ}\end{array}$ & $\begin{array}{l}145 \text { (zenith) } \\
118\end{array}$ & $\gamma_{s}>15^{\circ}$ & $\begin{array}{l}\text { CIE Sky } 12 \\
\text { clear sky }\end{array}$ & $\begin{array}{l}\text { Winter } 2015 \\
\text { (Jan - March) } \\
\text { Summer } 2015 \\
\text { (June - Aug) }\end{array}$ & $\begin{array}{l}1577 \\
(689+ \\
888)\end{array}$ & Figure 12 \\
\hline
\end{tabular}


Whereas most measurements used in this analysis were performed by the spectral sky scanner, the study investigating the difference between patch measurements and global measurements were conducted by means of spectroradiometer (specbos 1201 by JETI Technische Instrumente, Figure 6), calibrated in 2015, and characterised with a luminance standard at the start of the measuring series for this study. The spectroradiometer measures spectral radiance (opening angle $2^{\circ}$ ) or spectral irradiance with a diffusor and appropriate cosine correction.
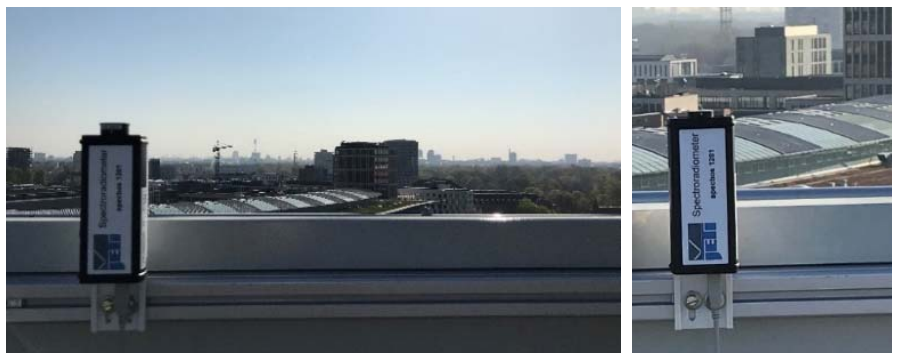

Figure 6 - Set-up for spectral global (left) and patch (right) measurements

\subsubsection{Representation of selected measurements}

A graphical representation of preliminary results is presented in Figure 7 to Figure 12. Statistical analysis of the data is not concluded yet. The results of the analysis will be used to formulate and refine the recommendations for spectral measurements in the template.
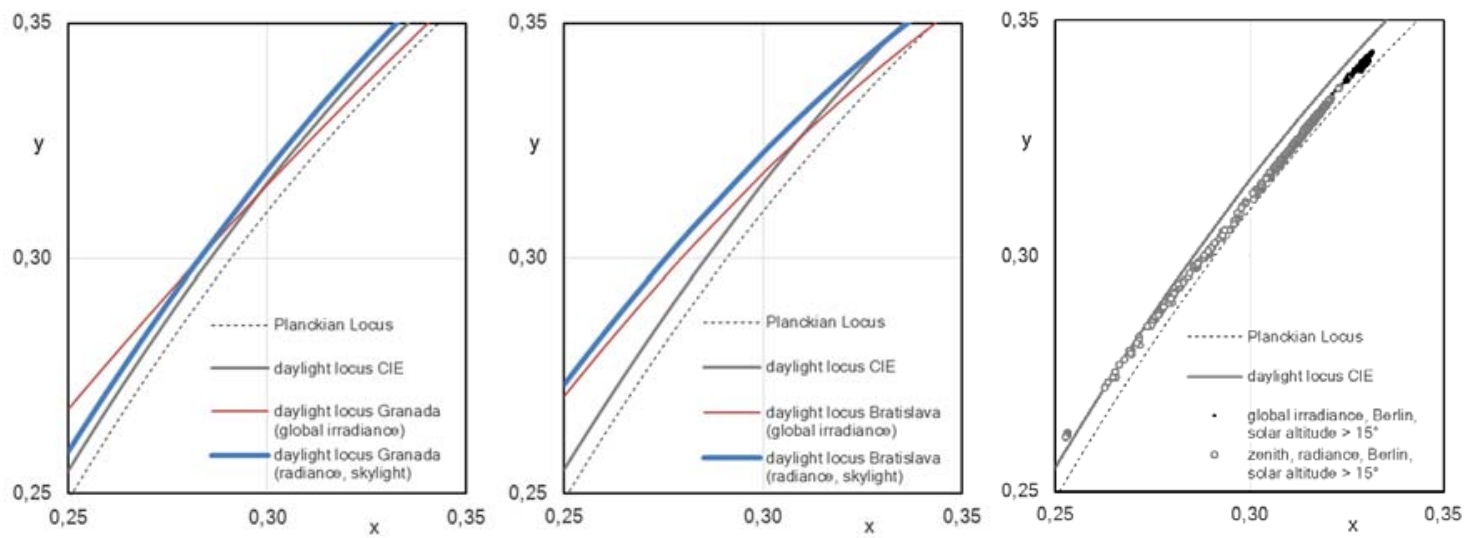

Figure 7 - Examples for daylight loci derived from global spectral irradiance measurements and from spectral radiance patch measurements (Granada - left, Bratislava - middle) and global and patch measurements obtained in Berlin (right)
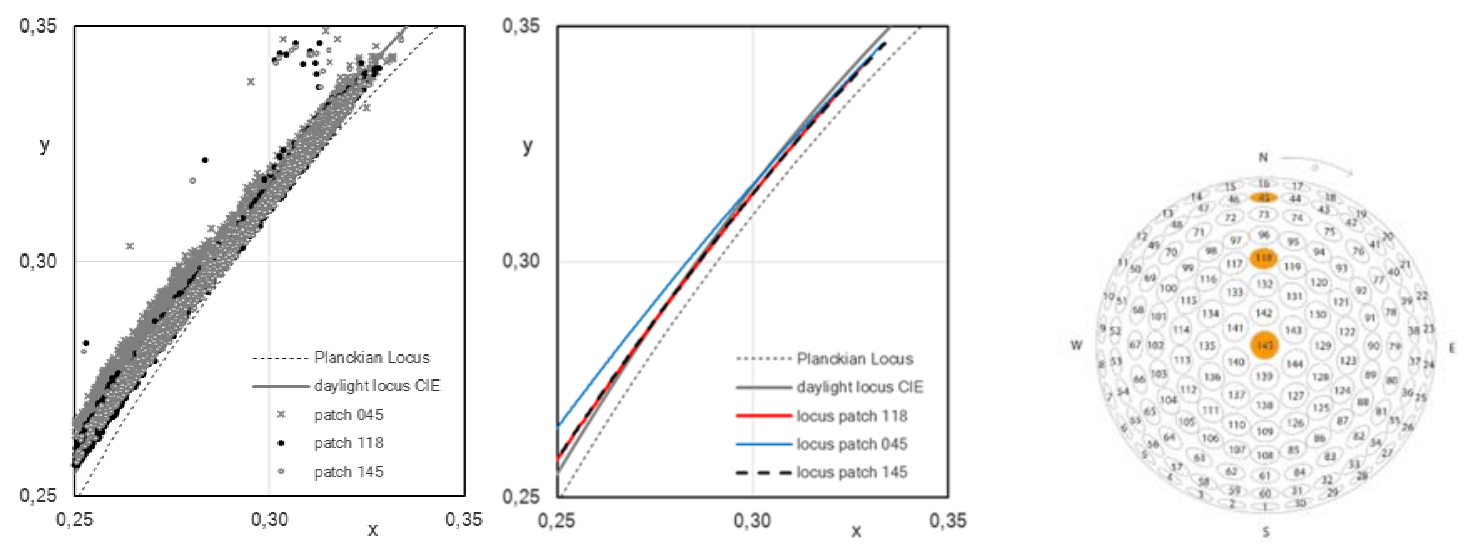

Figure 8 - Impact of $10^{\circ}$ detector direction: Zenith patch (nr. 145) measurements compared to patch 118 and patch 45 measurements (left), trend lines for patches (middle), location of patches (right) 

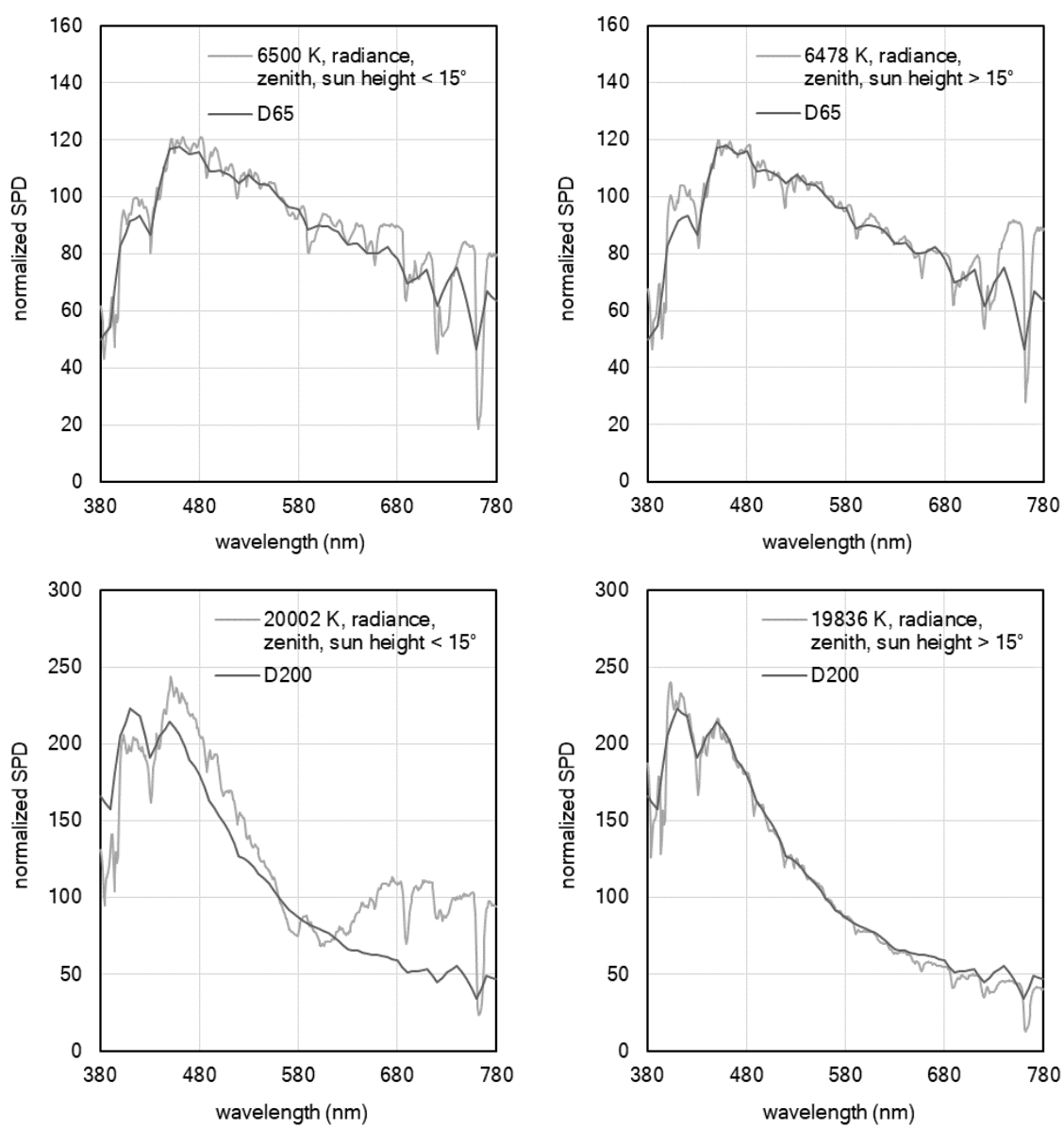

Figure 9 - Examples of SPDs for times with a solar altitude lower than $15^{\circ}$ (left) or higher than $15^{\circ}$ (right)
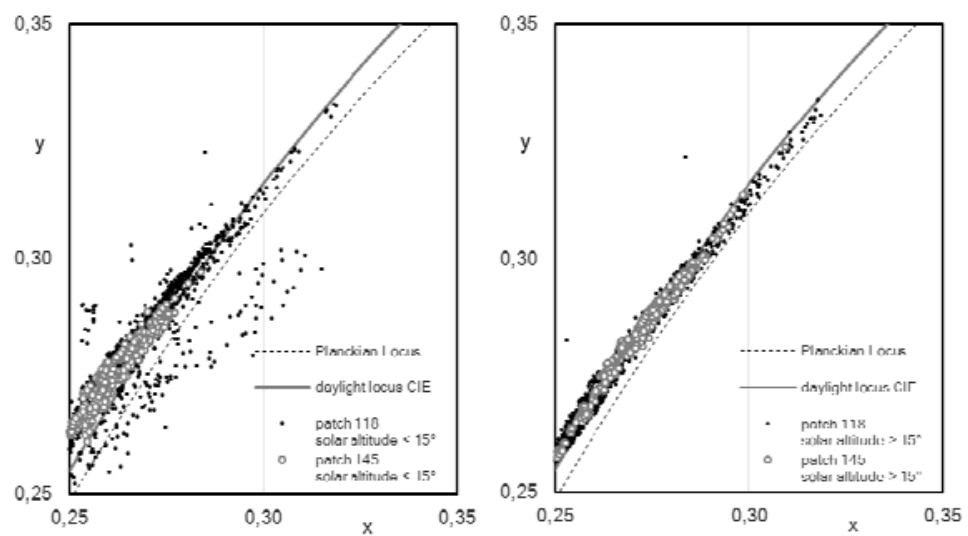

Figure 10 - Impact of solar altitude: Chromaticity coordinates $(x, y)$ of a selection of measurements throughout 2015 (CIE Sky Type 12, zenith patch and patch 118) for times with a solar altitude lower than $15^{\circ}$ (left) or higher than $15^{\circ}$ (right) 


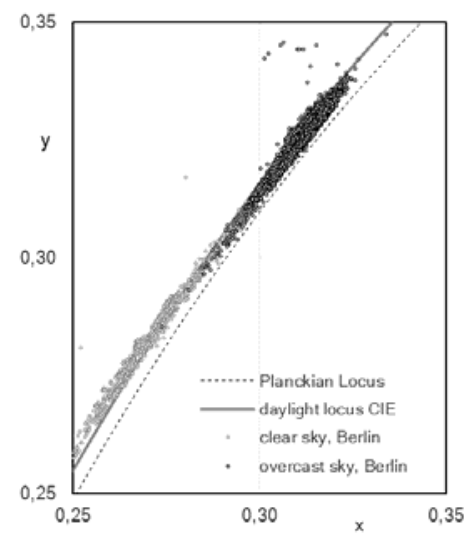

Figure 11 - Impact of sky type: Clear sky (CIE Sky Type 12) measurements compared to overcast sky (CIE Sky Type 3) measurements
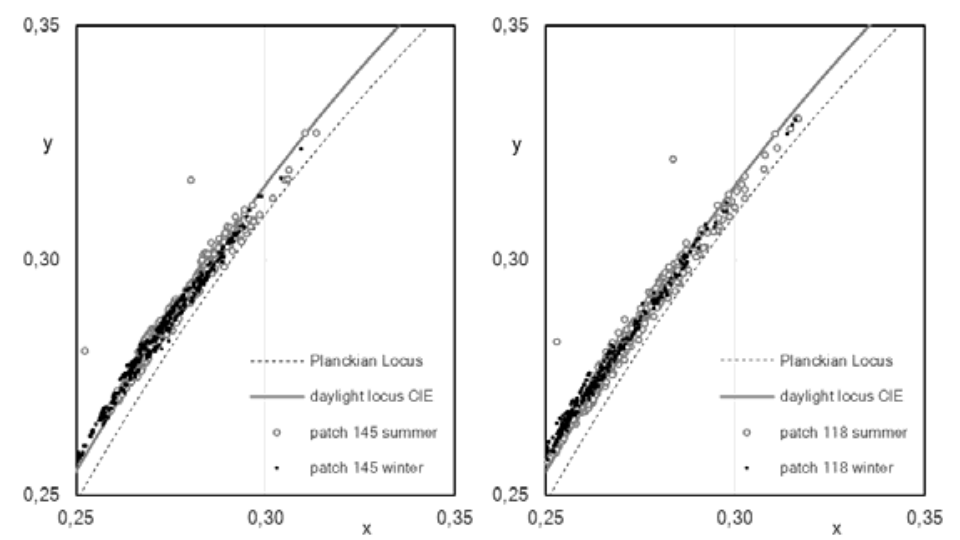

Figure 12 - Impact of season: Winter measurements compared to summer measurements for zenith sky patch 145 (left) and sky patch 118 (right) (refer for position Figure 8)

\subsubsection{Analysis}

The initial graphical analysis of measurements collected at the daylight measuring site of the Technische Universität Berlin shows relevant parameters to consider in the data collection to obtain information about geographical and seasonal differences, even though statistical analysis of the data is required to define the measurement protocol parameters in more detail. It indicates that solar altitude (Figure 10) and detector inclination (Figure 8, left and middle) for patch measurements are relevant parameters. Further analysis could be required to define whether global and patch measurements can be combined or need to be treated separately, as the results in this analysis do not confirm the findings of Hernández-Andrés et al. (2001-1, 20012) and Dubnicka et al. (2017) (Figure 7). Either way, the literature review and measurement analysis showed that the use of patch measurements, zenith or facing away from the sun, is recommended. With these measurements the required CCT bandwidth and thus SPDs to derive a local daylight locus and reconstruction approach is achieved. Sun facing and horizontal integral measurements will be predominated by the direct sunlight, reducing the CCT bandwidth and thus not offering the full range required to determine a local daylight locus (cf Figure 7 , right). Integral measurements turned away from the sun could be included, but should be well shielded for ground reflection, and the contribution from the area close to the horizon should be excluded, as it could affect the measurements (Figure 8). A differentiation in daylight loci for solar altitude ranges and almucantar ranges could be taken into account. Nonetheless, practical application and the relevance of an increased accuracy in the determination of, for example, IIL responses to daylight needs to be considered, and will be included in future research.

Whereas the CCT occurrence might vary for different seasons and different sky conditions (Collins 1965, Rusnák 2014, Diakite and Knoop 2019), the first analysis of measurements 
indicates that there is no seasonal nor a weather dependancy in the trend of the local daylight locus (Figure 11, Figure 12). The latter simplifies the documentation of measurements for the daylight locus and reconstruction evaluation, as prevailing sky type, typically derived from luminance measurements or cloud cover maps, is not an essential parameter to document.

Resulting, patch measurements, sky scanner measurements and a selection of integral measurements can be combined in a measurement campaign, when at least the recording date and time of day is included.

\section{Template}

This study will be concluded with a proposal for documentation and measurement to be used in measurement campaign, planned to modify or complement the existing CIE approach for reconstitution of daylight's spectral power distribution. This template can be found online (https://www.li.tu-berlin.de/menue/equipment/dms/indoor_daylight/template/) and will be updated after discussion at the conference. This documentation fits spectral radiance measurements conducted in a specific direction or collected by spectral sky scanners. It includes a template for the description of the measuring site, measuring equipment and measurements performed, as well as a template for data acquisition.

\section{References}

AYDINLI, S., BEHRENS, K., MASUCH J., RIECKE, W. 2016. Die Entwicklung der atmosphärischen Trübung in Deutschland. Konsequenzen für die Solarstrahlung. $H L H, 02$, 21-25

CHAIN, C. 2004. Caractérisation spectrale et directionnelle de la Lumière naturelle: Applicationàl Éclairage des Bâtiments. Thesis of ENTPE, Laborataire des Sciences de I'Habitat, Département Génie Civil et Bâtiment.

CIE 1967. CIE 14-1967. Recommendations on standard illuminants for colorimetry. In: CIE Washington Session. pp. 95-97.

CIE 1994. CIE 108:1994. Guide to recommended practice of daylight measurement. Vienna. CIE Central Bureau

CIE 2018. CIE 015:2018. Colorimetry. Vienna. CIE Central Bureau

COLLINS, J.F. 1965. The colour temperature of daylight. Br. J. Appl. Phys. 16, 527-532.

DIAKITE, A.K., WEBER, N., KNOOP, M. 2018. Optimierung des Verfahrens zur Rekonstruktion von Tageslichtspektren aus Farbörter auf dem Daylight Locus. In: Proceedings of LICHT 2018, Davos, Switzerland

DIAKITE A.K., KNOOP M. 2019. A data-driven colorimetric analysis of CIE Standard General Skies. To be published in: Proceedings of the $29^{\text {th }}$ session of CIE.

DIXON, E.R. 1978. Spectral distribution of Australian daylight. J. Opt. Soc. Am. 68, 437-450.

DUBNICKA, R., RUSNAK, A., KOMAR, L. DARULA, S., SMOLA, A. 2014. Spectroradiometric analysis of sky types. According to CIE document CIE S 011/E:2003. In: CIEx039:2014 Proceedings of CIE 2014 „Lighting Quality and Energy Efficiency” Conference. 708-715.

HENDERSON, S.T., HODGKISS, D. 1964. The spectral energy distribution of daylight. Brit. J. Appl. Phys., 15, 947-952.

HENDERSON, S.T.1977. Daylight and Its Spectrum. 2. Bristol: Hilger.

HERNÁNDEZ-ANDRÉS, J., ROMERO, J., GARCÍA-BELTRÁN, A., NIEVES, J.L. 1998. Testing linear models on spectral daylight measurements. Appl. Opt. 37, 971-977.

HERNÁNDEZ-ANDRÉS, J., ROMERO, J., \& LEE, R.L. (2001-1). Colorimetric and spectroradiometric characteristics of narrow-field-of-view clear skylight in Granada, Spain. J. Opt. Soc. Am.A. 18(2), 412-420. 
HERNÁNDEZ-ANDRÉS, J., ROMERO, J., NIEVES, J.L., \& LEE, R.L. (2001-2). Color and spectral analysis of daylight in southern Europe. J. Opt. Soc. Am. A, 18(6), 1325-1335.

HISDAL, V. 1987. Spectral distribution of global and diffuse solar radiation in Ny-Ålesund, Spitsbergen. Polar Res. 5(1), 1-27.

JUDD, D.B., MACADAM, D.L., WYSZECKI, G., BUDDE, H.W., CONDIT, H.R., HENDERSON, S.T., SIMONDS, J.L. 1964. Spectral distribution of typical daylight as a function of correlated color temperature. J. Opt. Soc. Am. 54(8), 1031-1040.

KOBAYASHI K., KAWAKAMI G., OKUMA Y., IKEMORI T. 1996. Spectral distribution of north sky daylight at Atsugi. Journal of the Illuminating Engineering Institute of Japan. 80(8),550553

KOK, C.J., CHALMERS, A.N., HENGSTBERGER, F. 1978. Measurement of the middle ultraviolet at Durban. Atmos. Environ. 12, 1119-1123.

KNOOP M., ABDELMAGEED A.A., LUO T., WEBER N., DIAKITE A.K. 2017. Spatially resolved spectral sky daylight measurement data: Methods of collection, evaluation and representation. In: Proceedings of the CIE 2017 Midterm Meeting, Jeju,(South Korea). 1036-1046,

NAYATANI, Y., WYSZECKI, G. 1963. Color of daylight from north sky. J. Opt. Soc. Am. 53(5), 626-629.

PEYVANDI, S., HERNÁNDEZ-ANDRÉS, J., OLMO, F. J., NIEVES, J. L., \& ROMERO, J. 2016. Colorimetric analysis of outdoor illumination across varieties of atmospheric conditions. $J$. Opt. Soc. Am. A, 33(6), 1049-1059.

RUSNÁK, A. 2014. Meranie a hodnotenie spektrálnych charakteristík slnečného žiarenia (Measurements and evaluation of spectral sun radiation characteristics, english translation by Dr. Darula). Thesis of University of Technology in Bratislava.

SASTRI, V.D P.; DAS, S R. 1968. Typical spectral distributions and color for tropical daylight. J. Opt. Soc. Am. 58(3), 391-398.

SEKINE, S. (1991). Spectral distributions of clear sky light and their chromaticities. J. Light Visual Environ. 15(1), 1_23-1_32.

TREGENZA P.R. 1987. Subdivision of the sky hemisphere for luminance measurements. Light. Res. Technol. 19(1), 13-14.

WINCH, G.T., BOSHOFF, M.C., KOK, C.J., DU TOIT, A.G. 1966. Spectroradiometric and colorimetric characteristics of daylight in the southern hemisphere: Pretoria, South Africa. J. Opt. Soc. Am. 56(4), 456-464. 